\title{
Análise biomecânica do joelho íntegro e com ruptura do ligamento cruzado cranial quanto ao grau de deslocamento cranial e rigidez articular em cães ${ }^{1}$
}

\author{
Biomechanical analisys of the normal knee and with cranial cruciate ligament rupture to \\ the cranial translation degree and articular stiffness in dogs
}

\author{
Leandro Romano ${ }^{2}$, Cezar Augusto Martins Pereira ${ }^{3}$, Alexandre Schmaedecke ${ }^{4}$, João Paulo Elsen Saut ${ }^{5}$, Cássio Ricardo \\ Auada Ferrigno ${ }^{6}$
}

1. Trabalho realizado na Faculdade de Medicina Veterinária e Zootecnia - USP.

2. Pós-graduando do Departamento de Cirurgia da FMVZ-USP

3. Tecnólogo em saúde. Especialista biomecânica do aparelho locomotor HC-FMUSP.

4. Mestre em Ciência. Doutorando do Departamento de Cirurgia da FMVZ-USP.

5. Mestre em Ciência. Doutorando do Departamento de Clínica da FMVZ-USP.

6. Professor Doutor do Departamento de Cirurgia da FMVZ-USP.

\section{RESUMO}

Objetivo: Avaliar a função biomecânica da articulação do joelho de cães, comparando a medida de deslocamento cranial e a rigidez articular da tíbia em relação ao fêmur em articulações íntegras e com ruptura de ligamento cruzado cranial. Métodos: Para realização do experimento foram utilizados 10 animas da espécie canina, com peso acima de 20 quilos. Avaliou-se biomecanicamente o grau de deslocamento da articulação do joelho com o ligamento cruzado cranial íntegro e seccionado cirurgicamente. Utilizou-se a máquina Kratos 5002, que permite gravar em tempo real os parâmetros força (N) e deslocamento/deformação em mm. O ensaio consitiu em aplicar uma força de (N) registrando assim a gaveta cranial. Resultados: Para o joelho íntegro, a média de deslocamento em milímetros encontrada para três repetições subseqüentes e estatisticamente diferentes entre si foram de 3,39;3,47; 3,53. Para o joelho lesado foram de 12,96; 13,24; 13,34. A análise estatística revelou diferença significante entre os dados do grupo íntegro e lesado, tanto para deslocamento quanto para rigidez $(p<0,05)$ Conclusão: Este estudo permite-nos concluir que a translação cranial é acrescida em quatro vezes e a rigidez articular é diminuída em uma vez e meia quando comparados.

Descritores: Biomecânica. Joelho. Ligamentos. Cães.

\begin{abstract}
Purpose: To analyse the biomechanical function of the knee joint in dogs, comparing the cranial translation degree and articular stiffness of the tibia in relation to the femur, in normal joints and joints with rupture of cranial crucial ligament. Methods: Ten mongrel dog knees were analyzed, weighting more than $20 \mathrm{~kg}$. Biomechanical analysis to the cranial translation degree of the knee joint with normal cranial cruciate ligament and surgically sectioned was made. Mechanical assays was realized by Kratos 5002 machine, and recorded in real time the parameters of force (N) and translation/ deformation, in $\mathrm{mm}$. The assay had consisted in to use a force $(\mathrm{N})$ registering the cranial translation. Results: To the normal knee, the deslocation media founded after 3 repetitions was 3,39; 3,47; 3,53. To the knee with surgical section was 12,96; 13,$24 ; 13,34$. The statistical analysis reveled significant diference between groups to the cranial tranlation e articular stiffness $(p<0,05)$. Conclusion: These study allows to conclude that the cranial translation is added in four times and the articular stiffness is reduced one and a half times when statistically compared.
\end{abstract}

Key words: Biomechanics. Knee. Ligaments. Dogs.

\section{Introdução}

Conhecido como ligamento "crucial" nos antigos textos de medicina humana, o ligamento cruzado cranial (LCC) tem como função bloquear movimento cranial anormal, a rotação interna da tíbia em relação a fêmur e prevenir a hiperextensão do membro ${ }^{1,2,4,10,11}$. A ruptura deste ligamento traz diversos graus de instabilidade durante toda amplitude de movimento, ${ }^{4,6,7}$ Há consenso na literatura mundial que o melhor tratamento para esta moléstia é cirúrgico, pois proporciona melhores resultados funcionais ${ }^{3,5,4,6,7}$ Porém, não há quantificação da movimentação articular anormal. Os ligamentos são estruturas dinâmicas. Sua anatomia e arranjo espacial estão diretamente relacionados ao funcionamento, como elementos de restrição do movimento articular ${ }^{4,8,9,14,15}$. Embora os relatos tenham trazido muita informação a respeito do LCC, a causa de sua ruptura freqüentemente não é conhecida e o modo ideal de tratamento permanece controverso ${ }^{12,13,21,22,23}$. O mecanismo e extensão destas lesões dependem da magnitude e direção 
da força traumática e da posição da articulação, no momento da aplicação desta força $a^{3,7,10,16,19,20}$. A lesão ligamentar pode de definir como ruptura completa, com grande instabilidade articular, ou a ruptura parcial com instabilidade de menor $\operatorname{grau}^{7,17,18}$. A instabilidade causada por lesão ligamentar aumenta o deslocamento cranial e diminui a rigidez articular trazendo alterações severas nas articulações acometidas. 10,16,19. Ensaios biomecânicos vêm sendo realizados no intuito de quantificar resultados que, antes hipotéticos, se baseavam apenas em estudos clínicos. Entretanto, é sabido que a avaliação biomecânica pode trazer informações importantes para estudos clínicos futuros. 1,5,7,10,12,13,17,19,20. Os principais estudos biomecânicos realizados até então buscam avaliar a eficácia de técnicas cirúrgicas e implantes. ${ }^{1,5,7,10,12,13,17,19,20,24}$. Não foram encontrados ensaios, na literatura pesquisada, que avaliem biomecanicamente a função do joelho íntegro e com ruptura do ligamento cruzado cranial utilizando cães como modelo experimental. Diante dos valores encontrados, foi possível aferir em quantas vezes o deslocamento cranial é acrescido e em quantas vezes a rigidez articular diminui, na relação entre joelho íntegro e com ruptura de ligamento cruzado cranial. Em ensaios futuros de técnicas reconstrutivas do ligamento cruzado cranial, é possível utilizar os resultados encontrados no joelho íntegro como parâmetros a se alcançar. Portanto, este trabalho comparou a diferença de deslocamento cranial e a rigidez articular, em joelhos com o ligamento cruzado cranial íntegro e em joelhos com ligamento cruzado cranial seccionado cirurgicamente.

\section{Métodos}

Para realização deste estudo foram utilizados 10 (dez) cadáveres de animas da espécie canina, machos ou fêmeas, com peso acima de 20 (vinte) quilos, com idade acima de 1 (um) ano e, a fim de padronização, somente foi utilizado o membro esquerdo de cada animal. Avaliou-se biomecanicamente o grau de deslocamento na articulação femoro-tíbio-patelar com o ligamento cruzado cranial íntegro e seccionado cirurgicamente, quanto ao grau de deslocamento da mesa tibial em direção cranial (movimento de gaveta cranial) e a rigidez articular da tíbia em relação ao fêmur. Para isto, foram impostas forças de tensão crescentes e estatisticamente diferentes entre si, próximas a $10 \mathrm{~kg}$ ou $100 \mathrm{~N}$, medindo o deslocamento em milímetros nos dois momentos citados anteriormente, em uma angulação de 45 graus. Para tanto, foi utilizada máquina universal de ensaios mecânicos Kratos 5002, dotada de célula de carga de 100 Kgf e ajustada para leitura na escala de $20 \mathrm{Kgf}$. A máquina foi acoplada ao computador através de sistema de aquisição de dados que permite gravar em tempo real os parâmetros força e deslocamento. O dispositivo tem a função de manter o joelho posicionado no ângulo desejado, e é composto por duas partes: a parte femoral teve como objetivo monitorar o deslocamento cranial (gaveta) quando uma força conhecida é aplicada, e a parte tibial, que permite 3 graus de liberdade, sendo eles a rotação e translação da tíbia em seu eixo principal e valgo/varo do joelho. Após a desinserção do fêmur através da abordagem da articulação coxo-femoral, o membro pélvico foi fixado à máquina de ensaios mecânicos Kratos 5002, para a tomada de medidas do instante 1 (ligamento íntegro). Para artrotomia foi empregado o acesso cutâneo lateral para exposição da fáscia femoral e do ligamento patelar. Em seguida realizou-se a diérese da cápsula articular lateral para a luxação da patela medialmente e inspeção da articulação e dos meniscos. O ligamento cruzado cranial foi transeccionado cirurgicamente e foi promovida a síntese em planos, segundo técnica consagrada. Neste momento foram realizadas novas mensurações, definindo assim o instante 2 (ligamento rompido). $\mathrm{O}$ ensaio consistiu em aplicar força de $5 \mathrm{~N}$ no sentido de inferior para superior produzindo deslizamento caudal, e após o retorno deste deslizamento (sentido inverso), foi aplicada força próxima a $100 \mathrm{~N}$ registrando assim a gaveta cranial. Os resultados foram expressos em forma de gráficos em tempo real, onde se obteve os parâmetros de força $(\mathrm{N})$ em função de deslocamento/deformação (gaveta) em mm, em três repetições (Figuras 1 e 2). Os valores foram comparados e expressos em forma de tabela nos dois momentos (articulação íntegra, ligamento rompido). Avaliouse o deslocamento e mobilidade do joelho após a secção cirúrgica em relação ao joelho íntegro e o grau de deformação apresentado.

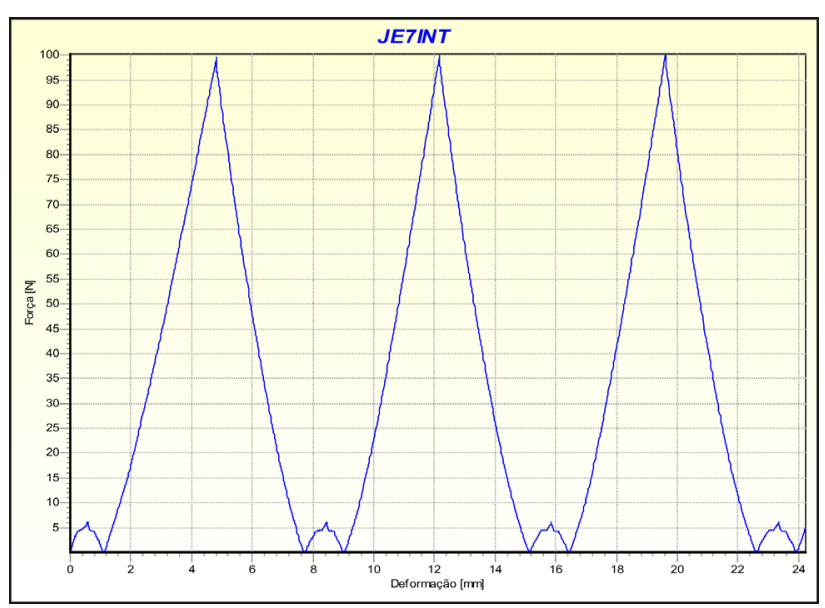

FIGURA 1 - Ensaio do joelho íntegro.

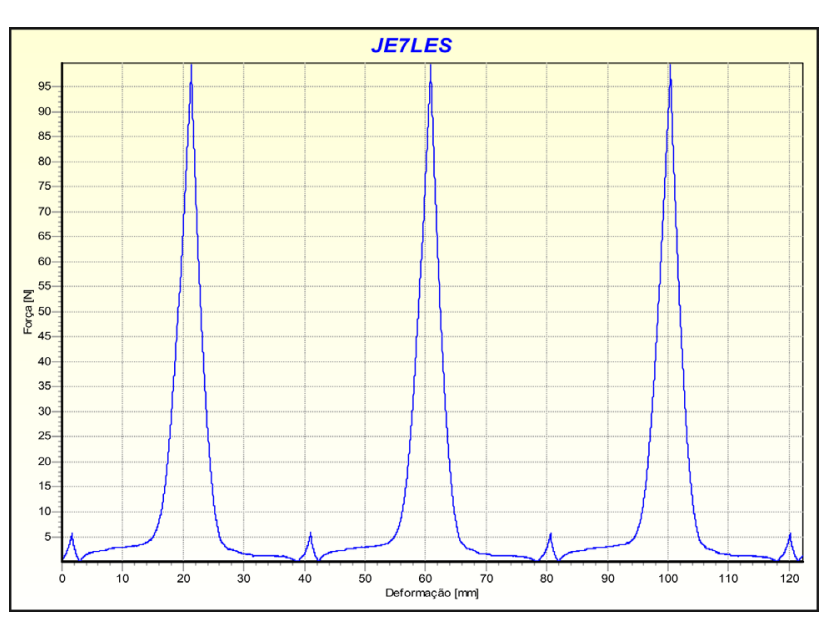

FIGURA 2 - Ensaio do joelho lesado. 


\section{Resultados}

Os resultados obtidos sobre a estabilidade do ligamento cruzado cranial, mensurado pelo limite de deslocamento cranial e pela rigidez ao deslocamento cranial da tíbia em relação ao fêmur, estão expressos na Tabela 1 . Foram obtidos, após análise estatística dos dados, os seguintes resultados:

Para o joelho íntegro, a média de deslocamento em milímetros encontrada para três repetições subseqüentes foram de 3,$39 ; 3,47 ; 3,53$. Um desvio padrão de 1,$06 ; 1,07 ; 1,10$, onde a mínima foi de 2,$44 ; 2,48 ; 2,48$ e a máxima 5,$85 ; 5,93 ; 6,04$, a média da rigidez articular foi de $37,52 \mathrm{~N} / \mathrm{mm}$, quando aplicada uma força de compressão de $10 \mathrm{~kg}$ ou $100 \mathrm{~N}$.

Para o joelho lesado, a média de deslocamento em milímetros encontrada para três repetições subseqüentes foram de 12,$96 ; 13,24 ; 13,34$. Um desvio padrão de 2,17;
2,$11 ; 2,10$, onde a mínima foi de 10,$73 ; 10,98 ; 11,07$, e a máxima 18,$02 ; 18,17 ; 18,19$, a média da rigidez articular foi de 23,65 $\mathrm{N} / \mathrm{mm}$, quando aplicada uma força de compressão de $10 \mathrm{~kg}$ ou $100 \mathrm{~N}$. Foi utilizado o teste estatístico de análise de variantes ANOVA, em 10 articulações, em dois grupos, íntegro e lesado, onde o valor $\mathrm{p}>0,05$ foi considerado significante. No teste de comparação múltipla Tukey-Kramer que compara os grupos entre si, o valor de "q" maior do que 3.509 e p>0,05, sendo amostra estatisticamente significante. No grupo íntegro, o valor de "q" encontrado foi de 3.388 e o valor em média do "q" encontrado no grupo lesado foi de 12.958. No teste de comparações múltipla Dunnett que coloca o grupo íntegro como controle, o valor de "q" maior do que 2.335 e p $>0,05$, sendo amostra estatisticamente significante. A comparação entre os grupos mostrou um "q" de 14.643.

TABELA 1 - Demonstrativo das forças aplicadas e resultados obtidos em relação ao deslizamento cranial (movimento de gaveta) e grau de rigidez articular, encontrados nos 10 joelhos testados.

\begin{tabular}{llllllllll}
\hline & Fcran1 & Fcran2 & Fcran3 & Gcran1 & Gcran2 & Gcran3 & Rig1 & Rig2 & Rig3 \\
\hline JE1INT & 98,88 & 98,96 & 99,01 & $\mathbf{5 , 8 5}$ & $\mathbf{5 , 9 3}$ & $\mathbf{6 , 0 4}$ & 25,51 & 29,60 & 29,60 \\
JE1LES & 98,91 & 99,06 & 99,08 & $\mathbf{1 4 , 4 2}$ & $\mathbf{1 4 , 6 5}$ & $\mathbf{1 4 , 7 7}$ & 18,72 & 22,49 & 22,74 \\
JE2INT & 100,18 & 100,42 & 100,45 & $\mathbf{4 , 1 5}$ & $\mathbf{4 , 3 4}$ & $\mathbf{4 , 4 3}$ & 28,44 & 35,84 & 38,98 \\
JE2LES & 100,26 & 100,22 & 100,30 & $\mathbf{1 3 , 7 0}$ & $\mathbf{1 3 , 7 8}$ & $\mathbf{1 3 , 8 3}$ & 23,49 & 24,20 & 24,15 \\
JE3INT & 101,05 & 101,11 & 101,26 & $\mathbf{5 , 8 1}$ & $\mathbf{5 , 9 2}$ & $\mathbf{6 , 0 3}$ & 46,35 & 49,30 & 49,83 \\
JE3LES & 100,25 & 100,23 & 100,67 & $\mathbf{1 3 , 8 9}$ & $\mathbf{1 4 , 1 8}$ & $\mathbf{1 4 , 4 0}$ & 23,83 & 26,64 & 29,35 \\
JE4INT & 99,84 & 101,14 & 101,38 & $\mathbf{3 , 7 3}$ & $\mathbf{3 , 7 6}$ & $\mathbf{3 , 8 4}$ & 35,94 & 38,84 & 39,75 \\
JE4LES & 99,68 & 99,63 & 99,78 & $\mathbf{1 1 , 6 8}$ & $\mathbf{1 1 , 8 8}$ & $\mathbf{1 1 , 9 7}$ & 20,65 & 24,86 & 25,80 \\
JE5INT & 100,39 & 100,76 & 100,88 & $\mathbf{2 , 4 4}$ & $\mathbf{2 , 4 8}$ & $\mathbf{2 , 4 8}$ & 47,47 & 54,21 & 56,30 \\
JE5LES & 99,88 & 100,31 & 100,46 & $\mathbf{1 0 , 9 9}$ & $\mathbf{1 1 , 3 9}$ & $\mathbf{1 1 , 5 3}$ & 29,21 & 35,92 & 35,81 \\
JE6INT & 100,42 & 100,91 & 100,85 & $\mathbf{2 , 6 3}$ & $\mathbf{2 , 7 3}$ & $\mathbf{2 , 7 7}$ & 44,10 & 55,63 & 56,19 \\
JE6LES & 99,89 & 100,18 & 100,07 & $\mathbf{1 1 , 5 9}$ & $\mathbf{1 2 , 0 7}$ & $\mathbf{1 2 , 1 1}$ & 29,24 & 32,87 & 34,37 \\
JE7INT & 99,65 & 100,06 & 100,27 & $\mathbf{3 , 6 9}$ & $\mathbf{3 , 7 9}$ & $\mathbf{3 , 8 6}$ & 30,47 & 36,29 & 36,58 \\
JE7LES & 99,89 & 100,18 & 100,07 & $\mathbf{1 8 , 0 2}$ & $\mathbf{1 8 , 1 7}$ & $\mathbf{1 8 , 1 9}$ & 20,41 & 21,89 & 21,88 \\
JE8INT & 100,37 & 100,58 & 100,80 & $\mathbf{4 , 5 7}$ & $\mathbf{4 , 7 2}$ & $\mathbf{4 , 8 9}$ & 36,45 & 44,84 & 45,26 \\
JE8LES & 99,88 & 100,10 & 100,34 & $\mathbf{1 6 , 2 0}$ & $\mathbf{1 6 , 2 7}$ & $\mathbf{1 6 , 1 3}$ & 22,68 & 24,07 & 24,83 \\
JE9INT & 101,35 & 101,16 & 101,52 & $\mathbf{2 , 6 9}$ & $\mathbf{2 , 7 8}$ & $\mathbf{2 , 8 5}$ & 44,89 & 53,18 & 53,42 \\
JE9LES & 99,96 & 100,42 & 100,41 & $\mathbf{1 1 , 8 3}$ & $\mathbf{1 2 , 1 6}$ & $\mathbf{1 2 , 2 3}$ & 26,36 & 29,93 & 30,75 \\
JE10INT & 100,17 & 100,34 & 100,45 & $\mathbf{2 , 7 4}$ & $\mathbf{2 , 7 7}$ & $\mathbf{2 , 8 0}$ & 45,66 & 51,09 & 51,08 \\
JE10LES & 99,80 & 99,97 & 100,00 & $\mathbf{1 3 , 1 0}$ & $\mathbf{1 3 , 4 1}$ & $\mathbf{1 3 , 5 5}$ & 22,01 & 23,46 & 24,56 \\
\hline
\end{tabular}

\section{Discussão}

A literatura referente contempla inúmeros trabalhos sobre o diagnóstico, patogenia, tratamentos conservativos ou cirúrgicos para a ruptura de ligamento cruzado cranial, bem como, os fatores de risco que talvez predisponham os cães, como, raça, idade, sexo e peso corpóreo inadequado. $2,3,4,6,8,9,14,15,18,21$. As técnicas cirúrgicas para estabilização articular e conseqüentes eliminação da translação cranial da tíbia em relação ao fêmur e prevenção da rotação interna excessiva surgem como tratamento de escolha de muitos cirurgiões, por trazerem melhores resultados clínicos no tocante a qualidade de vida e no retorno do membro à função. ${ }^{2,6,9,15,18,21,22}$ Entretanto, não se relatam mensurações biomecânicas da articulação femurotíbio-patelar com o ligamento cruzado cranial íntegro e lesado, quanto ao grau de deslocamento cranial da tíbia em relação ao fêmur e rigidez articular como parâmetros para comparação da estabilidade. Os trabalhos biomecânicos recentes visam avaliar técnicas cirúrgicas e compará-las entre si. ${ }^{1,5,7,10,12,13,17,19,20,22,23,24}$. Neste estudo, o objetivo foi encontrar valor em milímetros para joelho normal e comparar os resultados com o joelho lesado. Os resultados encontrados no joelho íntegro devem ser adotados como 
objetivo a ser alcançado em futuras avaliações de técnicas de reconstrução para reparação do ligamento cruzado cranial. A angulação de $45^{\circ}$ foi imposta em consenso com Arnoczky e Marshall ${ }^{3}$, que este é o ponto de movimento onde a articulação fica isenta de restrição. Adotamos a força de $100 \mathrm{~N}$ por ser padrão em ensaios anteriores em humanos $^{5,17,13}$ e segundo Gupta ${ }^{11}$, a força para romper o ligamento deve ser igual ou superior a 4 vezes o peso corpóreo do animal, então para animais com 20 quilos esta força seria insuficiente. Uma força de $5 \mathrm{~N}$ era imposta no sentido caudal, imitando uma translação articular caudal para que quando fosse realizada a translação cranial, no momento zero a força imposta já fosse de $100 \mathrm{~N}$, conforme estudo realizado por Kokron ${ }^{5}$. Apesar do ligamento cruzado cranial ser a estrutura primária de restrição articular, foi possível notar que as outras estruturas envolvidas tais como, cápsula articular, ligamento colateral lateral, ligamento patelar, fáscia lata e sistema muscular, por serem importantes fatores de estabilidade do joelho durante as atividades do paciente, trazem algum grau de restrição articular. Entretanto, este estudo verificou o joelho íntegro e o joelho com lesão isolada do ligamento cruzado cranial, sem avaliar as variantes envolvidas e a influência destas forças na estabilidade articular. Deve-se levar em conta de que os resultados se referem à lesão única do ligamento cruzado cranial e podem não ser aplicáveis a pacientes com lesões combinadas, o que exige estudos futuros sobre o tema. As forças de resistência exercidas pelos ligamentos, por serem estruturas dinâmicas restritoras de movimento, apresentavam-se, pela demonstração gráfica dos ensaios, imediatamente à ação da força de deslocamento impressa pela máquina. Já no joelho lesado, nota-se curva de resistência quase nula até o início da ação das demais estruturas de resistência articular acima descritas. Neste estudo, utilizando cães como modelo experimental, pode-se confirmar a idéia de que não só o deslocamento cranial, mas também a rigidez articular são importantes parâmetros de comparação de estabilidade na lesão do ligamento cruzado cranial, conforme descrito por Kokron $^{5}$, Barreto ${ }^{17}$ e Maderei Pereira ${ }^{13}$ em estudos com pacientes humanos. A rigidez articular está diretamente relacionada às estruturas retentoras de movimento que compõem a articulação, ou seja, ao analisar a articulação íntegra, o grau de rigidez articular é elevado, pois todas estruturas que envolvem a articulação, num certo momento, atuam em garantir rigidez extra ao componente articular e, conseqüente, pequeno grau de deslocamento cranial. Entretanto, ao romper-se o ligamento cruzado cranial, o grau de rigidez articular diminuía consideravelmente e o grau de deslocamento cranial aumentava. No tocante ao deslocamento cranial, em média, foi encontrada movimentação de 3,47 mm para o joelho íntegro e 13,24 para o joelho lesado, confirmando a análise de diversos autores, citando que a instabilidade articular causada pela lesão ligamentar traz alterações severas a longo prazo, e que a breve estabilização do joelho é o tratamento de escolha. ${ }^{2,3,6,8,9,14,18,21}$. Por fim os resultados obtidos neste estudo permitem concluir que em cães com ruptura do ligamento cruzado cranial a rigidez articular é diminuída em uma vez e meia e a translação cranial é acrescida de aproximadamente quatro vezes quando comparados isoladamente.
A reparação do ligamento cruzado cranial é de extrema importância. Entretanto, as técnicas cirúrgicas utilizadas devem buscar tanto a estabilização do joelho quanto ao deslocamento cranial, como também a promoção de rigidez articular.

\section{Referências}

1. Anderson CC, Tomlinson JL, Daly WR, Carson WL, Payne JT, Wagner-mann CC. Biomechanical evaluation of a crimp systen for loop fixation of monofilament nyulon leader material used for stabilization of the canine stifle joint. Vet Surg. 1998; 27: 533-9.

2. Arnoczky SP. Patomecânica das lesões do ligamento cruzado e meniscos. In: Bojrab MJ. Mecanismos da moléstia na cirurgia dos pequenos animais. São Paulo: 1996. p. 225-9.

3. Arnoczky SP, Marshall JL. The cruciate ligaments of the canine stifle: anatomical and funcional analysis. Am J Vet Res. 1977, 38: 1807-15.

4. Arnoczky SP, Rubin RN, Marshall JL. Microvasculature of the cruciate ligaments and its response to injury. J Bone Joint Surg. 1979, 61:1227-9.

5. Barreto JM. Avaliação mecânica da fixação femoral de tendões ísquio-tibiais e do ligamento patelar com parafuso de interferência nas reconstruções do ligamento cruzado anterior [Tese - Doutorado] Universidade de São Paulo Faculdade de Medicina; 2000.

6. Brinker WO, Piermattei DL, Flo GL. Aarticulação fêmurotíbio-patelar (joelho). In: Brinker WO, Piermattei DL, Flo GL. Manual de ortopedia e tratamento das fraturas dos pequenos animais. São Paulo 1999: p 346-70.

7. Caporn TM, Roe SC. Biomechanical evaluation of the suitability of monofilament nylon fishing and leader line for extra-articular stabilization of thr canine cruciate-deficiente stifle. Vet Comp Orthop Traumatol. 1996, 9: 126-33.

8. Dupuis J, Harari J. Cruciate ligament and meniscal injuries in dogs. Comp Cont. Edu Small Anim. 1993;15:215-32.

9. Fossum TW. Cranial cruciate ligament rupture. In: Fossum TW. Small animal surgery. St. Louis: 1997. p.957-66.

10. Gretchen KS, Meinen J, Philips T, Manley PA. Comparison of fishing nylon for repair of the cruciate deficiente stifle. Vet Comp Orthop Traumatol. 1999;129:138-41.

11. Gupta BN, Brinker WO, Subramanian KN. Breaking stregth of the cruciate ligaments in the dog. J Am Vet Med Assoc. 1969;155:1586-8.

12. Harper TAM, Martin RA, Ward DA, Grant JW. An in vitro study to determine the effectiveness of a patellar/ fascia lata graft and new suture anchor points for extracapsular stabilization of the cranial cruciate ligament deficient in the dog. Vet Surg. 2004;33(5):531-41.

13. Kokron AEV. Avaliação biomecânica da reconstrução na lesão isolada do ligamento cruzado posterior com um ou dois feixes de enxerto: estudo experimental com tendão do músculo quadríceps da coxa e com tendões dos músculos semitendíneo e grácil [Tese - Doutorado]. Universidade de São Paulo - Faculdade de Medicina; 2000.

14. Lampmam TJ, Lund EM, Lipowitz AJ. Cranial cruciate disease: current status of diagnosis, surgery, and risk 
for disease. Vet Comp Orthop Traumatol. 2003;16:122-6.

15. Leonard EP. Stfle joint. Orthopedic surgery of the dog and cat. Philadelphia: W.B. Saunders; 1971.

16. Lemburg AK, Meyer-lindenberg A, Hewicker-trautwein M. Immunohistochemical characterization of inflammatory cell populations and adhesion molecule expression in synovial membranes from dogs with spontaneous cranial cruciate ligament rupture. Vet Immunol Immunopathol. 2004;97(3-4):231-40.

17. Maderei Pereira JAR. Estudo biomecânico da influência da espessura do enxerto e da técnica de dois feixes na reconstrução do ligamento cruzado posterior [Tese Doutorado]. Universidade de São Paulo - Faculdade de Medicina; 2004.

18. Moore KW, Read RA. Rupture of the cranial cruciate ligament in dogs. Part II. Diagnosis and management. Compendium 1996;18:4:381-91.

19. Patterson RH. Smith GK. Gregor TP, Newton CD. Biomechanical stability of four cranial cruciate ligament repair techiniques in the dog. Vet Surg. 1991;20(5):85-90.

20. Peycke LE, Kerwin SC, Hosgood G, Metcalf JB. Mechanical coparison of six loop foxation methods with monofilament nylon leader line. Vet Comp Orthop Traumatol. 2002;4:210-4.

21. Piermattei DL, Flo GL. The stifle joints. Handbook of small animal orthopaedics and fracture repair. Philadelphia: W.B. Saunders 1997; p.516-80.

22. Prostedny JM. Effect of suture type on stifle joint biomechanics after extra-articular repair of cranial cruciate ligament transection in the dog. Vet Comp Orthop Traumatol. 1991;4:144-9.

23. Race A, Amis AA. In vitro biomchanical comparison of isometric versus single and double-bundled anatomic gafts. J Bone Joint Surg. 1998;80:173-9.

24. Vasseur PB. Correlative biomechanical and histologic study of the cranial cruciate ligament in dogs. Am J Vet Res. 1985;46(9):1842-54.
Correspondência:

Leadro Romano.

RuaCapitãoTeófilo,36.Centro

07013-055 GUARULHOS-SP
Conflito de interesse: nenhum Fonte de financiamento: Fapesp

Recebimento: 03/09/2005

Revisão: $13 / 10 / 2005$

Aprovação: 16/11/2005

\section{Como citar este artigo:}

Romano L, Pereira CAM, Schmaedecke A, Saut JPE, Ferrigno CRA. Análise biomecânica do joelho íntegro e com ruptura do ligamento cruzado cranial quanto ao grau de deslocamento cranial e rigidez articular em cães. Acta Cir Bras. [periódico na Internet] 2006 Jan-Fev;21(1). Disponível em URL: http:/www.scielo.br/acb

*Figuras coloridas disponíveis em http://www.scielo.br/acb 